\title{
Symptoms and impact of COPD assessed by an electronic diary in patients with moderate-to- severe COPD: psychometric results from the SHINE study
}

\author{
This article was published in the following Dove Press journal: \\ International Journal of COPD \\ 7 January 2015 \\ Number of times this article has been viewed
}

\author{
Károly Kulich' \\ Dorothy L Keininger' \\ Brian Tiplady ${ }^{2}$ \\ Donald Banerji ${ }^{3}$
}

'Novartis Pharma AG, Basel, Switzerland; ${ }^{2}$ Research Technologies Ltd, Peterborough, UK; ${ }^{3}$ Novartis Pharmaceuticals Corporation, East Hanover, NJ, USA
Correspondence: Donald Banerji Novartis Pharmaceuticals Corporation, I Health Plaza, East Hanover, NJ 07936, USA

Tel +l 862778952 I

Email donald.banerji@novartis.com
Background: Symptoms, particularly dyspnea, and activity limitation, have an impact on the health status and the ability to function normally in patients with chronic obstructive pulmonary disease (COPD).

Methods: To develop an electronic patient diary (eDiary), qualitative patient interviews were conducted from 2009 to 2010 to identify relevant symptoms and degree of bother due to symptoms. The eDiary was completed by a subset of 209 patients with moderate-to-severe COPD in the 26-week QVA149 SHINE study. Two morning assessments (since awakening and since the last assessment) and one evening assessment were made each day. Assessments covered five symptoms ("shortness of breath," "phlegm/mucus," "chest tightness," "wheezing," and "coughing") and two impact items ("bothered by COPD" and "difficulty with activities") and were scored on a 10-point numeric scale.

Results: Patient compliance with the eDiary was $90.4 \%$ at baseline and $81.3 \%$ at week 26 . Correlations between shortness of breath and impact items were $>0.95$. Regression analysis showed that shortness of breath was a highly significant $(P<0.0001)$ predictor of impact items. Exploratory factor analysis gave a single factor comprising all eDiary items, including both symptoms and impact items. Shortness of breath, the total score (including five symptoms and two impact items), and the five-item symptom score from the eDiary performed well, with good consistency and reliability. The eDiary showed good sensitivity to change, with a 0.6 points reduction in the symptoms scores (on a $0-10$ point scale) representing a meaningful change.

Conclusion: The eDiary was found to be valid, reliable, and responsive. The high correlations obtained between "shortness of breath" and the ratings of "bother" and "difficulty with activities" confirmed the relevance of this symptom in patients with COPD. Future studies will be required to explore further psychometric properties and their ability to differentiate between COPD treatments.

Keywords: QVA149, psychometric assessment, dyspnea, health status, patient-reported outcomes

\section{Introduction}

Symptoms, particularly dyspnea and activity limitation, have a profound impact on the activities of daily life and health status in patients with COPD. ${ }^{1}$ The prevention and control of symptoms are important elements in the management of COPD as the goals have shifted towards optimizing symptom control and reducing future risks such as exacerbations, hospital admissions, and deaths. ${ }^{1}$

These symptoms are frequently collected as a patient-reported outcome (PRO) from either a questionnaire, diary, or clinical questionnaire. ${ }^{2,3}$ PROs are recognized 
as important outcomes in clinical research, and particularly in respiratory indications such as asthma and COPD, where specific treatment outcomes can only be captured from the patient. ${ }^{4}$ PROs are increasingly being collected by electronic means (electronic PROs or ePROs). ${ }^{5-7}$ The electronic collection of data is particularly helpful in unsupervised settings, where paper-based diaries may be less valid because of suboptimal patient adherence to diary completion. ${ }^{8,9}$

PRO instruments, either paper or electronic based, need to be validated in order to be reliable and responsive to clinically meaningful treatment effects. PRO instruments should also facilitate easy understanding and usage to the patients and physicians and be relevant and acceptable to the healthcare providers and regulatory authorities, respectively. ${ }^{10}$

The guidelines published by the US Food and Drug Administration provide a useful framework for collection of adequate psychometric data in order to document that PRO measures are fit for purpose. ${ }^{11}$ Here, we present the results of psychometric assessment data from a COPD eDiary developed by Novartis to provide a more detailed assessment of the symptoms and their impact on patients with COPD.

Qualitative patient interviews were conducted from 2009 to 2010 to elicit concepts from patients in the US, identifying relevant symptoms as well as degree of bother because of symptoms. The COPD eDiary was administered to a subset of patients in the 26-week SHINE study, ${ }^{12}$ which was a part of the Phase III clinical trial program on QVA149, a once-daily dual bronchodilator containing a fixed-dose combination of the long-acting $\beta_{2}$ agonist indacaterol and the long-acting muscarinic antagonist glycopyrronium. ${ }^{12-15}$

\section{Methods}

\section{Study design and treatments}

The COPD eDiary was completed twice a day (morning and evening) for 26 weeks by a subset of patients in the SHINE study. (See Supplementary materials for more details of the SHINE study, including institutional review and consent procedures). Data for the following visits were used for psychometric validation: baseline (the day treatment started), week 1 ( 7 days after baseline), week 12, and week 26 (end of the study). In each case, the eDiary data were used from the 7-day period preceding the visit. The site-based PRO assessments (St George's Respiratory Questionnaire [SGRQ], baseline dyspnea index [BDI], and transitional dyspnea index [TDI]) were made at baseline, week 12, and week 26.

\section{Patient population}

The SHINE study included male and female patients aged $\geq 40$ years with moderate-to-severe stable COPD (stage II or III according to the Global Initiative for Chronic Obstructive Lung Disease 2008 criteria), a smoking history of $\geq 10$ pack-years, and a postbronchodilator forced expiratory volume in 1 second $\left(\mathrm{FEV}_{1}\right) \geq 30 \%$ and $<80 \%$ of the predicted normal and postbronchodilator $\mathrm{FEV}_{1}$ to forced vital capacity ratio of $<0.70$ at screening. ${ }^{12}$

\section{Objectives}

The objectives of the current analysis were to determine the frequency of occurrence and the severity of COPD symptoms in this patient group; to determine how bothersome and difficult patients find their COPD symptoms; and to establish the measurement properties of the COPD eDiary.

\section{Assessments/measures COPD eDiary}

The morning assessment of the COPD eDiary had two components: M1, from waking up until completing the morning assessment, and M2, from the last scheduled diary entry (the evening before) until completing the morning assessment. The evening assessment (E) covered the period from the last scheduled diary entry (morning of the current day) until completing the evening assessment.

Each assessment included five symptom items: "shortness of breath", "phlegm/mucus", "chest tightness", "wheezing", and "coughing". Two impact items, "bothered by COPD" and "difficulty with activities" were also captured, with the latter being evaluated in M2 and E only. "Bothersomeness" was included in all the three eDiary time frames as part of exploring the impact of symptoms on patients' lives. It has been reported that the health-related quality of life in patients with COPD correlates more strongly with the ratings of dyspnea or symptoms than does the spirometry. ${ }^{18,19}$ All the items were rated on an eleven-point numeric scale from 0 (none) to 10 (worst possible). (For further details, please refer to Supplementary materials.)

\section{Clinic-based instruments}

The SGRQ was used to assess the health status of patients in the study. ${ }^{3}$ Dyspnea was measured at baseline using BDI and during the treatment period using TDI, which captured changes from baseline as interviewed by a trained assessor. A TDI focal score of 1 is considered to be a clinically significant improvement from baseline. ${ }^{20}$

\section{Statistical analysis}

The analysis used the available data from all patients who completed the COPD eDiary. Compliance rates were 
assessed as percentage of scheduled entries over each assessment period.

Frequencies of occurrence for individual symptoms (score $>0$ ) are presented, and an overall mean symptom score was calculated for the five symptom items over the baseline and week 26 periods. Correlations were calculated for the baseline scores using the mean item scores over the 7-day baseline period.

The exploratory factor analysis was performed on the baseline 7-day mean scores (by time frame) using principal components analysis. Parallel analysis was used to determine the optimal number of factors to extract. ${ }^{21}$

The internal consistency of the eDiary was evaluated using Cronbach's coefficient alpha $(\alpha)$. Test-retest reliability was assessed using the mean of the 7-day baseline scores as the test and the mean of the 7-day week 1 scores as the retest in patients who rated themselves unchanged from baseline in the weekly assessment of change in the eDiary. Reliability was calculated using the intraclass correlation coefficient (ICC), form 2,1.22

Sensitivity to change for eDiary was evaluated using the change from baseline to week 26. Patients were classified into three groups, "improved," "worse," or "uncertain/no change," based on $\mathrm{FEV}_{1}$ and ratings on the global items of the diary at week 26 . The change scores were then compared for these three improvement groups.

\section{Results}

\section{Patient demographics}

Two hundred and nine patients were allocated to the COPD eDiary, of whom 140 (67.0\%) were male and 69 (33.0\%) were female. Ages ranged from 44 to 86 years; 92 patients $(44.0 \%)$ were under 65 years, $80(38.3 \%)$ were $\geq 65$ years to $<75$ years, and $37(17.7 \%)$ were $\geq 75$ years.

\section{eDiary assessment schedule compliance}

The mean compliance rates over the study were $90.1 \%$ for baseline, $88.9 \%$ for week $1,84.6 \%$ for week 12 , and $80.0 \%$ for week 26. The mean compliance rates for the M1 and M2 compared to E were $86.5 \%$ and $84.5 \%$, respectively, over the 26-week study period.

\section{Frequency and severity of reporting of COPD symptoms}

All five symptoms in the eDiary were present in $\geq 50 \%$ of entries, with shortness of breath, phlegm/mucus, and cough occurring in more than $70 \%$ of entries over the study period. Overall, slightly lower frequencies for M1 were observed compared with M2 or E (Figure 1A). The mean symptom
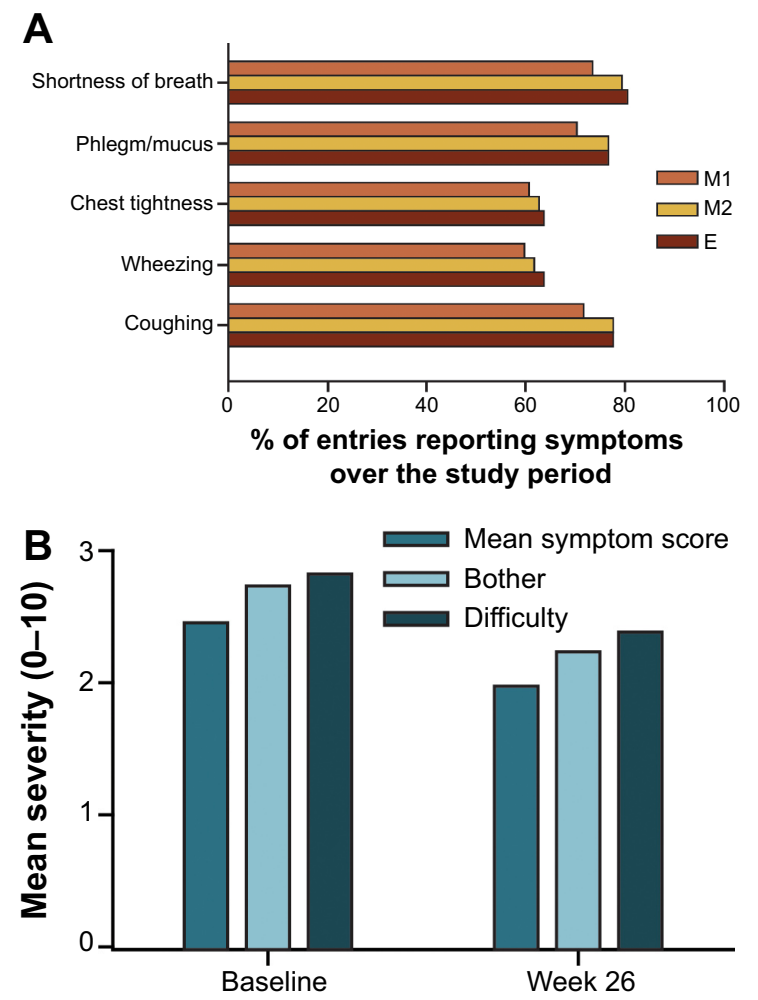

Figure I Frequency of occurrence $(\mathbf{A})$ and severity of COPD symptoms (B) over the study period.

Abbreviations: COPD, chronic obstructive pulmonary disease; E, evening diary; MI, morning diary: symptoms since awakening; M2, morning diary: symptoms since the last assessment.

score severity ranged between 1.6 and 3.2 (on a $0-10$ point scale), with severity being greater at baseline than at the end of the study (Figure 1B). The severity of mean "bother" and "difficulty with activities" scores occurred in the range of 2.0-2.6 over the course of the study.

\section{Distribution properties}

The mean scores for all items (five symptoms and two impact items) were in the range of 2.12-3.20 for baseline and 1.682.60 for week 26 , with the scores being positively skewed.

\section{Correlations between symptom severity and bother/difficulty with activities scores}

The correlations between the scores for the five diary symptoms and impact items at baseline were high, with $>0.7$ for bother and $>0.6$ for difficulty with activities across all assessments (Table 1). A very high correlation was observed between shortness of breath and impact items ( $>0.95$ across all assessments).

For other symptoms, correlations with impact items were lower but still substantial (0.64-0.86). Regression modeling showed that shortness of breath was a highly significant $(P<0.0001)$ predictor of bother ratings, with no other 
Table I Correlations (Pearson's $r$ ) between individual symptoms and overall bother/difficulty with activities caused by COPD symptoms at baseline

\begin{tabular}{|c|c|c|c|c|c|c|c|c|c|c|}
\hline & \multicolumn{2}{|l|}{ MI } & \multicolumn{4}{|l|}{ M2 } & \multicolumn{4}{|l|}{$\mathbf{E}$} \\
\hline & $r$ & $\rho$ & $r$ & & $\rho$ & & $r$ & & $\rho$ & \\
\hline Symptom & B & B & B & $\mathrm{D}$ & B & $\mathrm{D}$ & B & $\mathrm{D}$ & B & $\mathrm{D}$ \\
\hline Shortness of breath & 0.957 & 0.939 & 0.956 & 0.953 & 0.932 & 0.940 & 0.958 & 0.958 & 0.940 & 0.943 \\
\hline Phlegm/mucus & 0.763 & 0.682 & 0.718 & 0.688 & 0.647 & 0.618 & 0.675 & 0.661 & 0.618 & 0.611 \\
\hline Chest tightness & 0.856 & 0.831 & 0.861 & 0.858 & 0.834 & 0.838 & 0.844 & 0.849 & 0.832 & 0.836 \\
\hline Wheezing & 0.798 & 0.728 & 0.782 & 0.761 & 0.732 & 0.700 & 0.722 & 0.706 & 0.645 & 0.640 \\
\hline Coughing & 0.733 & 0.662 & 0.688 & 0.639 & $0.595^{*}$ & $0.556 *$ & 0.656 & 0.644 & $0.572^{*}$ & $0.566^{*}$ \\
\hline
\end{tabular}

Notes: *Indicates correlations within probable "moderate" range of $0.300-0.600$, inclusive; correlations are presented for the mean scores over I-week periods; only weeks with at least four diary assessments are included in the analysis.

Abbreviations: B, bother; COPD, chronic obstructive pulmonary disease; D, difficulty, E, evening diary; MI, morning diary: symptoms since waking; M2, morning diary: symptoms since last assessment; $r$, Pearson's correlation coefficient; $\rho$, Spearman's correlation coefficient.

symptom showing a significant association once shortness of breath had been taken into account.

\section{eDiary factor structure}

The exploratory factor analysis gave a single factor comprising all seven eDiary items (five symptoms and two impact items), and this was found when the three time frames (M1, $\mathrm{M} 2$, and $\mathrm{E}$ ) were combined or when the time frames were assessed separately (Table 2). At least $75 \%$ of the variance was accounted for by the first factor in all cases.

\section{Internal consistency of eDiary}

A very high internal consistency, evaluated using all seven diary items, was found with Cronbach's coefficient $\alpha$, with all values being $>0.95$ for all three assessment time points (baseline, week 12, and week 26) and for all three eDiary time frames (Table 3).

\section{Test-retest reliability of eDiary}

A total of 44 patients reported no change in their condition between baseline and week 1 . As a single factor was found, the mean of all seven eDiary items was used as the total score. The ICC for the combined scores for all the measures assessed

Table 2 Factor loadings for the single factor identified by exploratory factor analysis (EFA) using baseline data

\begin{tabular}{lllll}
\hline Item & \multicolumn{4}{l}{ Assessment points } \\
\cline { 2 - 5 } & MI & M2 & E & Overall \\
\hline Shortness of breath & 0.942 & 0.947 & 0.944 & 0.953 \\
Phlegm/mucus & 0.901 & 0.853 & 0.839 & 0.861 \\
Chest tightness & 0.921 & 0.922 & 0.913 & 0.921 \\
Wheezing & 0.900 & 0.885 & 0.845 & 0.874 \\
Coughing & 0.865 & 0.824 & 0.812 & 0.828 \\
Bother & 0.942 & 0.952 & 0.944 & 0.954 \\
Difficulty with activities & - & 0.939 & 0.942 & 0.933 \\
\hline
\end{tabular}

Abbreviations: $\mathrm{E}$, evening diary; $\mathrm{MI}$, morning diary: symptoms since awakening; M2, morning diary: symptoms since the last assessment. (individual eDiary items, five-item symptom mean, sevenitem overall mean) from the three assessment time frames (M1, M2, and E) was $>0.94$, with the lower confidence limit being $>0.90$. The ICC was $>0.95$ for the two summary means (symptom mean of five items and total mean of seven items), for all the three assessment time frames. A high reliability was also observed for the individual seven diary items, with ICC ranging between 0.95 and 0.98 .

\section{Validity of eDiary}

Table 4 shows the correlations among the various PRO measures at baseline. For the BDI, the highest correlation with the eDiary items was found for the magnitude of effort item and the lowest for functional impairment, with the magnitude of task being intermediate. This pattern was found also for all the individual eDiary items, with the partial exception of phlegm/ mucus (magnitude of task $>$ functional impairment) as well as for the summary scores. The correlations of the individual items with BDI were generally in the following order: difficulty with activities $>$ bother $>$ shortness of breath $>$ chest tightness $>$ wheezing $>$ phlegm $/$ mucus $\cong$ coughing.

For SGRQ, the correlation pattern for the activity and impact subscales was similar to that of BDI, with difficulty with activities, bother, and shortness of breath showing the highest correlations. Two of the three highest values within columns were as predicted, whereas the third, that is, the correlation between eDiary difficulty with activities and SGRQ symptoms was not as predicted. Thus, the observed pattern only partly fulfilled the predictions. (For further details, please refer to results in the Supplementary materials.)

\section{Sensitivity to change}

Patients were classified as improved $(n=33)$ or uncertain/no change ( $\mathrm{n}=135$ ) using both the clinical and patient global measures as discussed earlier in the Statistical analysis 
Table 3 Internal consistency estimates for eDiary items

\begin{tabular}{lllll}
\hline & \multicolumn{4}{l}{ Cronbach's coefficient $\alpha$} \\
\cline { 2 - 5 } & Overall mean & MI & M2 & E \\
\hline Baseline & 0.96 & 0.96 & 0.96 & 0.96 \\
Week 12 & 0.96 & 0.95 & 0.96 & 0.96 \\
Week 26 & 0.96 & 0.95 & 0.96 & 0.96 \\
\hline
\end{tabular}

Abbreviations: $\mathrm{E}$, evening since the last assessment; eDiary, electronic patient diary; MI, morning diary: symptoms since awakening; M2, morning diary: symptoms since the last assessment.

section. The eDiary was sensitive to change, as determined by the observed change in the eDiary scores. The Cohen's effect size for the change over the 26-week study period was large (0.79) in the improved patient group (corresponding to a reduction of 1.23 points in the total mean score) compared with a minimal change $(0.16)$ in the uncertain/no change patient group (corresponding to a reduction of 0.29 points).

The SGRQ data gave less clear-cut discrimination between the improved and nonimproved patient groups (Figure 2). This clinic-based measure showed Cohen's effect sizes of 0.60 and 0.24 for the improved and uncertain/ no change patient groups, respectively. The evaluation of change over various periods suggested that the 26 -week study period was appropriate for assessing the improvement in this population of patients with COPD.

\section{Clinically meaningul change in the scores}

Table 5 shows the changes in the eDiary scores for overall impact and severity of COPD from baseline to week 26 that are associated with a rating of "a little better." Changes in TDI scores associated with "minor improvement" on functional impairment, magnitude of task, and magnitude of effort items are also included in Table 5. In all cases, the change scores were $0.5-0.6$, suggesting that an improvement of 0.6 points on the eDiary overall mean score could be considered as a meaningful change for the patient.

\section{Discussion}

The results clearly emphasize the importance of shortness of breath as a key symptom of COPD.

Management of COPD in an optimal manner is key, as it is progressive and complex in nature. PROs allow objective assessment of the patients' condition and might lead to informed decision by the physician for effective management of COPD in patients. Results from previously conducted interviews in patients with COPD provided an insight to frame appropriate content in this COPD eDiary. In our analysis, we found that shortness of breath showed the highest correlation with the impact items (bother and difficulty with activities) of the eDiary items. Regression analysis showed that no other symptom was a predictor of the bother scores once shortness of breath had been accounted for. Shortness of breath, together with the bother and difficulty with activities items, showed the highest loading on the single factor identified by the exploratory factor analysis; this was substantially higher than those found with other eDiary items. Thus, shortness of breath is the most important symptom in determining the impact of COPD on the patient. The results also indicate the strong connection between COPD symptoms and impacts. These scores (on a 0-10 point scale) are comparable with those of the symptoms themselves and indicate that bothersomeness and difficulty with activities are broadly in line with the levels of symptoms experienced (Figure 1B). In some therapeutic areas, such as pain, there are only modest correlations between measures of symptom severity and indicators of impact, or the data indicate that severity and impact items load onto distinct factors. ${ }^{26,27}$ This appears not to be the case here, with a single factor including all symptoms and impact items, and high correlations among symptom and impact items.

In the current analysis, there was a predominance of male over female patients and a mean age of approximately

Table 4 Spearman's correlation between eDiary (overall) and the SGRQ and BDI scores at baseline

\begin{tabular}{|c|c|c|c|c|}
\hline & & \multicolumn{3}{|c|}{ eDiary score (mean of the three assessment time frames) } \\
\hline & & Symptom mean & Bother & Difficulty with activities \\
\hline & & \multicolumn{3}{|l|}{ Spearman's correlation } \\
\hline \multirow[t]{3}{*}{ SGRQ subscale score } & Activity & 0.485 & 0.564 & 0.610 \\
\hline & Impacts & 0.577 & 0.634 & 0.647 \\
\hline & Symptoms & 0.609 & 0.541 & 0.560 \\
\hline \multirow[t]{3}{*}{ BDI } & Magnitude of effort & -0.433 & -0.516 & -0.525 \\
\hline & Functional impairment & -0.282 & -0.332 & -0.358 \\
\hline & Magnitude of task (at normal pace) & -0.349 & -0.395 & -0.421 \\
\hline
\end{tabular}

Notes: Correlations were negative for BDI, where the higher scores represent better states, and positive for SGRQ, where the higher scores represent worse states. Values in bold are predicted to be the highest because of concordance between measurement concepts.

Abbreviations: BDI, baseline dyspnea index; eDiary, electronic patient diary; SGRQ, St George's Respiratory Questionnaire. 


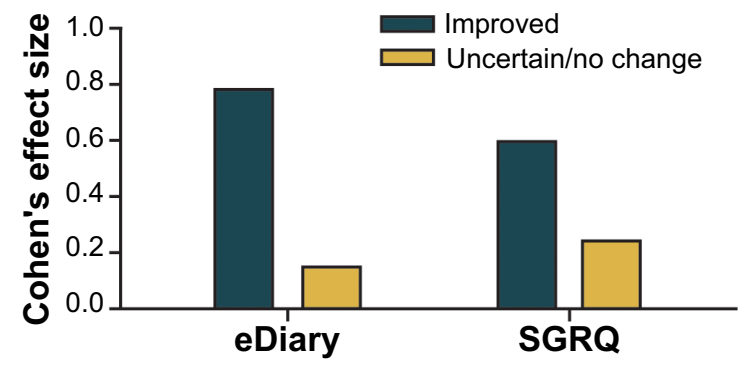

Figure 2 Sensitivity to change of the eDiary at week 26. Abbreviations: eDiary, electronic patient diary; SGRQ, St George's Respiratory Questionnaire.

65 years, which is typical of populations recruited into clinical research of COPD. ${ }^{23,24}$ The compliance rate of patients with the eDiary ranged from approximately $90 \%$ at the beginning of the study to approximately $80 \%$ over 26 weeks. Although these compliance rates were not as high as those achieved in some previous eDiary studies, ${ }^{7,8}$ the completion rates of $\geq 80 \%$ are considered good for eDiary assessments. ${ }^{27}$ This suggests that the eDiary was not unduly arduous for patients to capture the information. No symptoms were considered for exclusion from the eDiary because of either too low frequency or severity.

However, both frequency and severity of symptoms were somewhat less for the M1 assessment (symptoms since awakening) than for the M2 and E, both of which measured symptoms since the previous assessment. This can be expected as the M1 assessment covered a shorter interval than the M2 or E entry. The severity and frequency of the symptoms decreased somewhat over the study period as expected. The two items in the eDiary that assessed impact (bother and difficulty with activities) showed similar values and patterns to the symptom items. All items showed a degree of skewness and marked floor effects, although these were not extreme. The correlation and factor structure of the eDiary showed that it behaved as a single one-dimensional measure.

The exploratory factor analysis showed a single factor solution, with particularly high factor loadings for bother and shortness of breath. Taken together with the high internal consistency of the eDiary ratings, these results showed that the seven-item overall diary mean, including impact and symptoms, can be used as a single summary measure.

The COPD eDiary demonstrated a robust reliability with an ICC of $>0.95$ for the two eDiary mean scores (five-item symptom mean score and total score comprising all seven eDiary items) and $>0.93$ for shortness of breath symptom. For comparison, ICCs obtained from PRO measures from a clinicbased study in COPD were in the range of 0.82-0.95. ${ }^{28}$

Evaluations of validity used correlations between eDiary assessments and other PRO measures in the study. The initial prediction was that correlations for related items would be higher than those for unrelated items.

However, as noted above, the eDiary showed a singlefactor structure, with a strong link between the symptom and impact items. Thus, it is not surprising that the findings related to the correlation of eDiary symptoms and the symptom mean with SGRQ and TDI were weaker and less consistent than initially predicted, although the expected patterns were apparent to a substantial degree. These patterns overall supported the validity of the eDiary as a measure of PRO severity and impact. The eDiary was sensitive to change, as determined by the observed change in the eDiary scores in a group of patients identified as having improved on both the clinical and patient global measures. The effect size for the change over the 26-week study period was large in this group compared with a minimal change in patients classified as uncertain/no change. These results are consistent with the Cohen's classification of effect sizes, with 0.2 being small, 0.5 medium, and 0.8 large, ${ }^{29}$ and showed that the eDiary is capable of demonstrating change in COPD severity and discriminating between patients showing important change and those who do not. The effect sizes for the eDiary gave a greater discrimination between the improved and uncertain/ no change patients than those for the SGRQ, suggesting that the eDiary had advantages over this clinic-based measure in terms of sensitivity to change.

Table 5 Reductions in the overall eDiary mean total score with the lowest level of improvement on each scale at week 26

\begin{tabular}{lll}
\hline Rating & Items & Change in eDiary total mean at week 26 \\
\hline eDiary rating "a little better" & Overall impact & -0.61 \\
& Severity of COPD & -0.58 \\
TDI rating "minor improvement" & Functional impairment & -0.64 \\
& Magnitude of task & -0.52 \\
& Magnitude of effort & -0.55 \\
\hline
\end{tabular}

Abbreviations: COPD, chronic obstructive pulmonary disease; eDiary, electronic patient diary; TDI, transitional dyspnea index. 
Anchor-based comparison using the patient global ratings of change suggested that a change of 0.6 on the total mean score of the eDiary represented a meaningful change for patients.

The main limitation of this study was that the sample was not large enough to make more than preliminary assessment of the ability of the eDiary to discriminate between treatment effects. This will require the use of the eDiary in larger comparative studies. The number included was, however, adequate to address the main objectives relating to the measurement properties of the instrument.

In conclusion, the results from the analysis indicated that the new eDiary contents and time frames were appropriate. Strong correlations with the clinic-based PRO measures supported the validity of the eDiary, and these were also found to be internally consistent, reliable, and sensitive to change. Future studies will be required to explore further psychometric properties and their ability to differentiate between novel COPD treatments.

\section{Acknowledgment}

The authors were assisted in the preparation of this manuscript by Saurabh Aggarwal and Kevin Roche (Novartis).

\section{Disclosure}

Brian Tiplady is an employee of eResearch Technologies Ltd. He also works independently as a research consultant in the area of cognitive testing, and holds shares in AstraZeneca. Donald Banerji and Dorothy L Keininger are employees of Novartis. Károly Kulich was an employee of Novartis at the time of manuscript preparation. The SHINE study was sponsored by Novartis Pharma AG and is registered at ClinicalTrials.gov with the clinical trial identifier number NCT01202188. The authors report no other conflicts of interest in this work.

\section{References}

1. Global Initiative for Chronic Obstructive Lung Disease (GOLD). Global Strategy for the Diagnosis, Management, and Prevention of Chronic Obstructive Pulmonary Disease. 2014 update [webpage on the Internet]. Global Initiative for Chronic Obstructive Lung Disease, Inc.; 2014. Available from: http://www.goldcopd.org/guidelines-global-strategyfor-diagnosis-management.html. Accessed July 11, 2014.

2. Wedzicha JA, Donaldson GC. Exacerbations of chronic obstructive pulmonary disease. Respir Care. 2003;48(12):1204-1213.

3. Jones PW, Quirk FH, Baveystock CM. The St George's Respiratory Questionnaire. Respir Med. 1991;85(Suppl B):25-31.

4. Deshpande PR, Rajan S, Sudeepthi BL, Abdul Nazir CP. Patient-reported outcomes: A new era in clinical research. Perspect Clin Res. 2011;2(4): 137-144.

5. Byrom B, Tiplady B, editors. ePRO: Electronic Solutions for PatientReported Data. Surrey: Gower; 2010.
6. Ireland AM, Wiklund I, Hsieh R, Dale P, O'Rourke E. An electronic diary is shown to be more reliable than a paper diary: results from a randomized crossover study in patients with persistent asthma. J Asthma. 2012; 49(9):952-960.

7. Bjorner JB, Rose M, Gandek B, Stone AA, Junghaenel DU, Ware JE. Method of administration of PROMIS scales did not significantly impact score level, reliability, or validity. J Clin Epidemiol. 2014; 67(1):108-113.

8. Stone AA, Shiffman S, Schwartz JE, Broderick JE, Hufford MR. Patient non-compliance with paper diaries. BMJ. 2002;324(7347): 1193-1194.

9. Stull DE, Leidy NK, Parasuraman B, Chassany O. Optimal recall periods for patient-reported outcomes: challenges and potential solutions. Curr Med Res Opin. 2009;25(4):929-942.

10. Jones P, Miravitlles M, van der Molen T, Kulich K. Beyond $\mathrm{FEV}_{1}$ in COPD: a review of patient-reported outcomes and their measurement. Int J Chron Obstruct Pulmon Dis. 2012;7:697-709.

11. US Department of Health and Human Services Food and Drug Administration. Guidance for Industry: Patient-Reported Outcome Measures: Use in Medical Product Development to Support Labeling Claims; 2009. Silver Spring, MD: FDA. Available from: www.fda. gov/downloads/Drugs/GuidanceComplianceRegulatoryInformation/ Guidances/UCM193282.pdf. Accessed February 18, 2014.

12. Bateman ED, Ferguson GT, Barnes N, et al. Dual bronchodilation with QVA149 versus single bronchodilator therapy: the SHINE study. Eur Respir J. 2013;42(6):1484-1494.

13. Vogelmeier CF, Bateman ED, Pallante J, et al. Efficacy and safety of once-daily QVA149 compared with twice-daily salmeterol-fluticasone in patients with chronic obstructive pulmonary disease (ILLUMINATE): a randomised, double-blind, parallel group study. Lancet Respir Med. 2013;1(1):51-60.

14. Dahl R, Chapman KR, Rudolf M, et al. Safety and efficacy of dual bronchodilation with QVA149 in COPD patients: the ENLIGHTEN study. Respir Med. 2013;107(10):1558-1567.

15. Wedzicha JA, Decramer M, Ficker JH, et al. Analysis of chronic obstructive pulmonary disease exacerbations with the dual bronchodilator QVA149 compared with glycopyrronium and tiotropium (SPARK): a randomised, double-blind, parallel-group study. Lancet Respir Med. 2013; 1(3):199-209.

16. Baldwin MJ, Kulich K, Tiplady B, Gwaltney C, Cline J. Evaluation of an electronic daily diary for measuring morning symptoms in chronic obstructive pulmonary disease. Am J Respir Crit Care Med. 2013;187: A2517.

17. Baldwin M, Kulich K, Tiplady B, Gwaltney C, Cline J. Symptoms and impact of COPD assessed by a handheld electronic diary. Poster presented at: 2013 Meeting of the European Respiratory Society; September 7-11, 2013; Barcelona, Spain. Poster P4903.

18. Mahler DA, Faryniarz K, Tomlinson D, et al. Impact of dyspnea and physiologic function on general health status in patients with chronic obstructive pulmonary disease. Chest. 1992;102(2):395-401.

19. Tsiligianni I, Kocks J, Tzanakis N, Siafakas N, van der Molen T. Factors that influence disease-specific quality of life or health status in patients with COPD: a review and meta-analysis of Pearson correlations. Prim Care Respir J. 2011;20(3):257-268.

20. Mahler DA, Weinberg DH, Wells CK, Feinstein AR. The measurement of dyspnea. Contents, interobserver agreement, and physiologic correlates of two new clinical indexes. Chest. 1984;85(6): $751-758$.

21. O'Connor BP. SPSS and SAS programs for determining the number of components using parallel analysis and velicer's MAP test. Behav Res Methods Instrum Comput. 2000;32(3):396-402.

22. Shrout PE, Fleiss JL. Intraclass correlations: uses in assessing rater reliability. Psychol Bull. 1979;86(2):420-428.

23. Hilleman DE, Dewan N, Malesker M, Friedman M. Pharmacoeconomic evaluation of COPD. Chest. 2000;118(5):1278-1285. 
24. Jones PW, Donohue JF, Nedelman J, Pascoe S, Pinault G, Lassen C. Correlating changes in lung function with patient outcomes in chronic obstructive pulmonary disease: a pooled analysis. Respir Res. 2011;12:161.

25. Kerns K, Decker SN. Multifactorial assessment of reading disability: identifying the best predictors. Percept Mot Skills. 1985;60(3): 747-753.

26. Fraenkel L, Falzer P, Fried T, et al. Measuring pain impact versus pain severity using a numeric rating scale. J Gen Intern Med. 2012;27(5): $555-560$.
27. Morren M, van Dulmen S, Ouwerkerk J, Bensing J. Compliance with momentary pain measurement using electronic diaries: a systematic review. Eur J Pain. 2009;13(4):354-365.

28. Mahler DA, Ward J, Waterman LA, McCusker C, Zuwallack R, Baird JC. Patient-reported dyspnea in COPD reliability and association with stage of disease. Chest. 2009;136(6):1473-1479.

29. Cohen J. Statistical Power Analysis for the Behavioral Sciences. New York, NY: Academic Press; 1977. 


\section{Supplementary materials COPD patient eDiary}

There were two diaries used in the SHINE study: main and exploratory. The main diary was completed by the majority of patients in the study and was reported previously. ${ }^{1}$ Chronic obstructive pulmonary disease (COPD) exploratory electronic patient diary (eDiary), the subject of the present analysis, was used in a subset of 209 patients. ${ }^{2,3}$ The COPD exploratory eDiary was completed twice a day (morning and evening) throughout the study period where patients were randomized through Interactive Voice Response System. The exploratory eDiary, unlike the main diary, did not trigger alarm when symptoms worsened, and patients were instructed to contact the site when needed.

The severity and frequency of symptoms may not be the same as bothersomeness. Some symptoms might be frequent and severe but not as bothersome as others, even less frequent or severe. "Bothersomeness" and "difficulty with activities" were included in the eDiary to increase the ability to pick up these distinctions, which are likely to be important from the patient's perspective. In addition, there were questions on the use of rescue medication (salbutamol/albuterol), awakenings, and a weekly assessment of change from baseline, rating symptoms, and impact on daily life. The SHINE study was approved by the independent ethics committee or the institutional review boards of each participating center and was conducted in accordance with the International Conference on Harmonization Guidelines for Good Clinical Practice and the Declaration of Helsinki. All patients provided written and signed informed consent before enrollment. The version of the eDiary used is shown below (Figure S1).

\section{Statistical analysis}

A multiple regression analysis approach was used to assess the relationship between the individual symptoms rated in the COPD eDiary and the assessment of bothersomeness. Validation used correlations between the eDiary assessments and other patient-reported outcome measures in the study at baseline, with a priori predictions concerning the convergence of items/subscales on the basis of content, specifically activities, impacts, and symptoms. The primary analysis used the St George's Respiratory Questionnaire (SGRQ), which had a structure (symptoms, activities, and impacts) similar to that of the exploratory diary. A Spearman's correlation matrix was presented for all the individual diary item scores, the total symptom score against the three factor scores, and the total from the SGRQ. Patients were classified as "improved" if they showed improvements of at least $120 \mathrm{~mL}$ in forced expiratory volume in 1 second $\left(\mathrm{FEV}_{1}\right)$ and had rated improvement on both global items in the week 26 diary (ie, "a little better," "moderately better," or "a great deal better" for both items).

\section{Complete in the MORNING}

\section{[Sleep items]}

Please answer these questions thinking about your sleep last night.

1. How many times did you wake up during the night because of your COPD symptoms?

$$
\text { Enter number }
$$

2. How long have you been awake today?

$\begin{array}{ll}\square & <30 \text { minutes } \\ \square & 30 \text { minutes }-1 \text { hour } \\ \square & 1 \text { hour }-2 \text { hours } \\ \square & 2 \text { hours }-3 \text { hours } \\ \square & 3 \text { hours }-4 \text { hours } \\ \square & >4 \text { hours }\end{array}$

(Continued) 


\section{[Sleep/wake transition items]}

Please answer the next questions thinking about the time between when you woke up today and until now.

3. Did you take your rescue medication between when you woke up and until now?

Yes

No

4. Please rate the severity of your shortness of breath between when you woke up and until now.

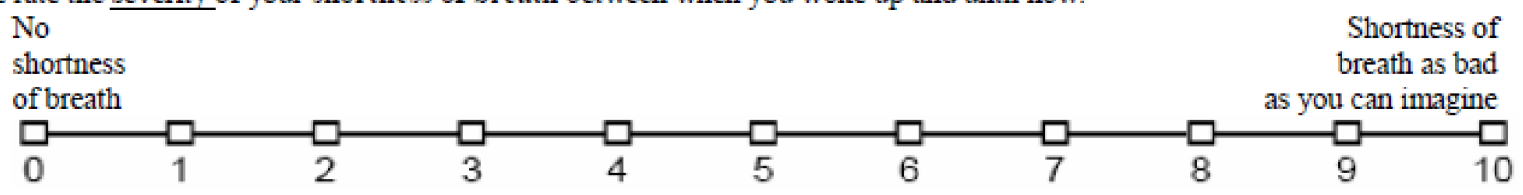

5. Please rate the difficulty you had clearing the phlegm/mucus from your lungs between when you woke up and until now.

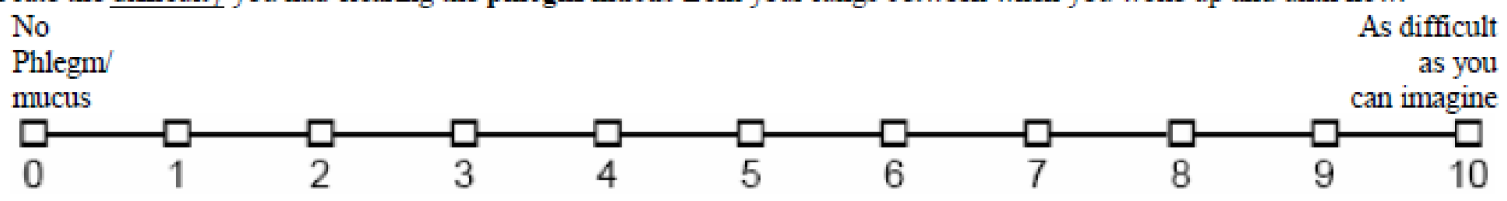

6. Please rate the severity of your chest tightness between when you woke up and until now.

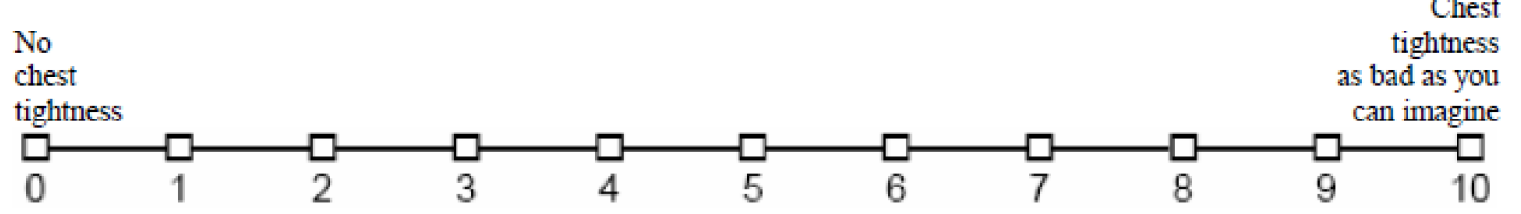

7. Please rate the severity of your wheezing between when you woke up and until now.

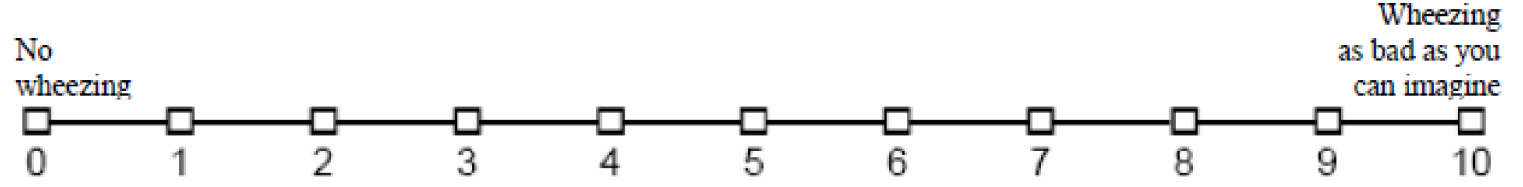

8. Please rate the severity of your coughing between when you woke up and until now.

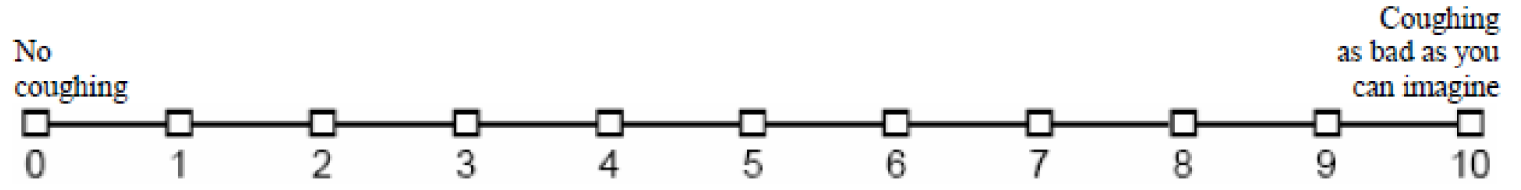

9. Please rate how bothered you were by your COPD symptoms between when you woke up and until now.

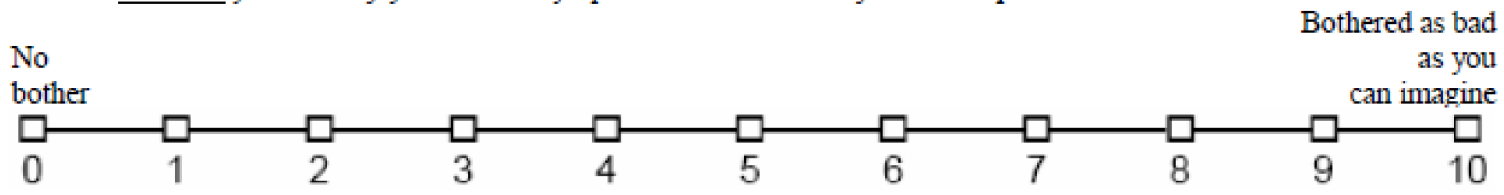

Figure SI (Continued). 


\section{[Symptoms since last assessment]}

Please answer the next questions thinling about the time between yesterday evening (last scheduled diary) and now.

10. How many puffs of your rescue medication did you take between yesterday evening and until now?

\section{Enter number}

11. Please rate the severity of your shortness of breath when it was at its worst between yesterday evening and until now

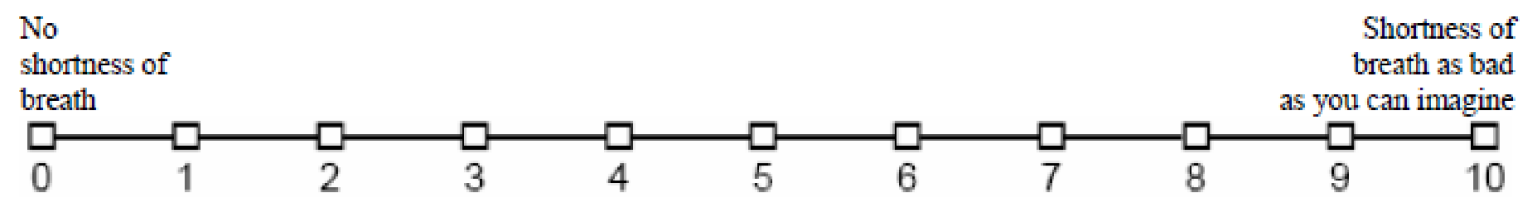

12. What was your activity level just before your shortness of breath was at its worst?

Resting (For example: sitting or lying down)

Mild (For example: walking within your home, bathing, or dressing)

Moderate (For example: walking while carrying a light load, sweeping floors, or vacuuming)

Vigorous (For example: walking briskly, dancing, or climbing stairs)

13. Please rate the difficulty you had clearing the phlegm/mucus from your lungs when it was at its worst between yesterday evening and until now.

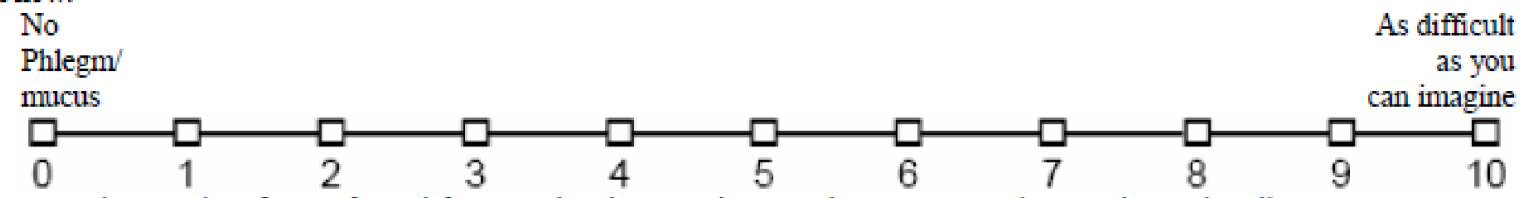

14. Please rate the severity of your chest tightmess when it was at its worst between yesterday evening and until now.

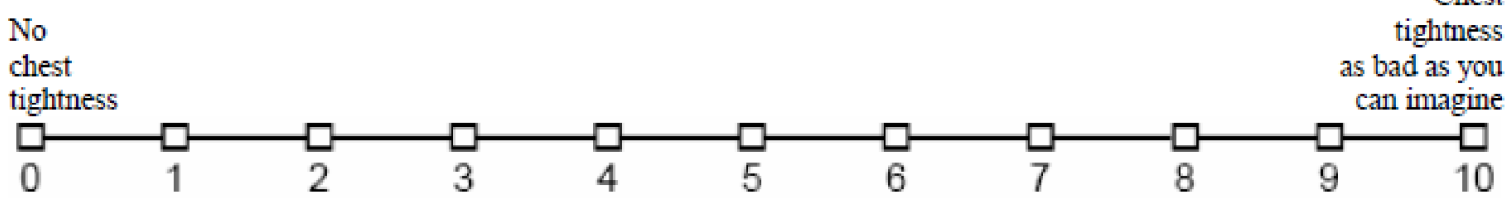

15. Please rate the severity of your wheezing when it was at its worst between yesterday evening and until now.

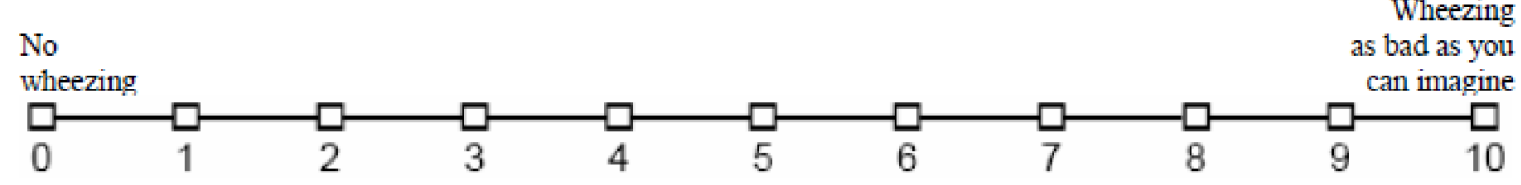

16. Please rate the severity of your coughing when it was at its worst between yesterday evening and until now. No as bad as you

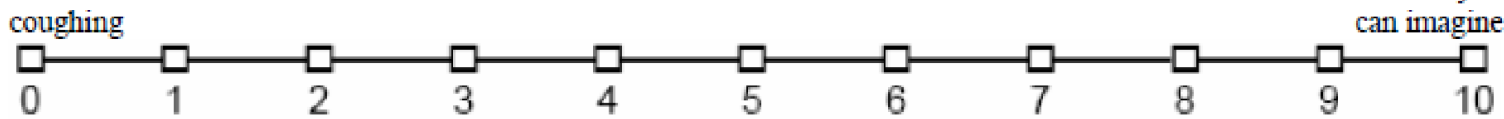

Figure SI (Continued). 
17. Please rate how bothered you were by your COPD symptoms between yesterday evening and until now.

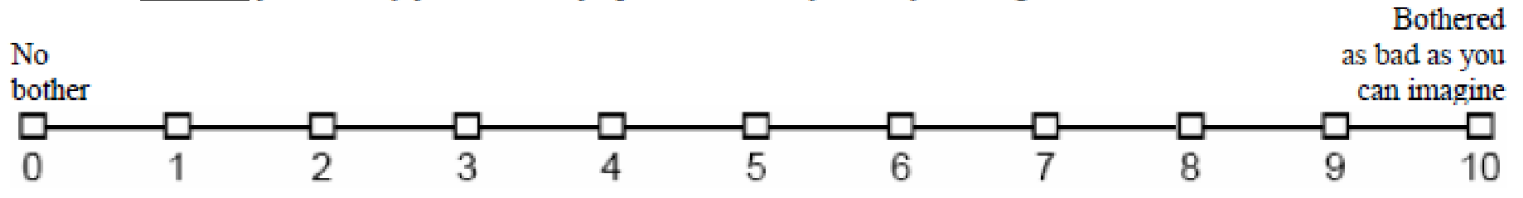

18. Please rate how difficult your COPD symptoms made it for you to move around or do your activities between yesterday evening and until now.

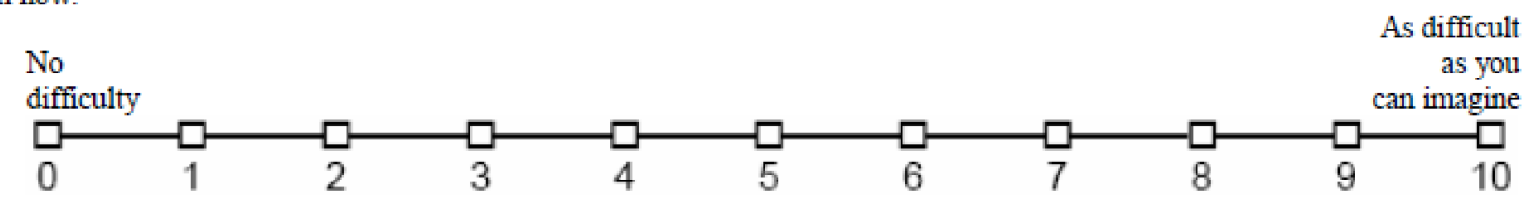

\section{Complete in the EVENING}

Please answer the next questions thinking about the time between this morning (last scheduled diary) and now.

1. How many puffs of your rescue medication did you take between this morning and until now?

Enter number

2. Please rate the severity of your shortness of breath when it was at its worst between this morning and until now.

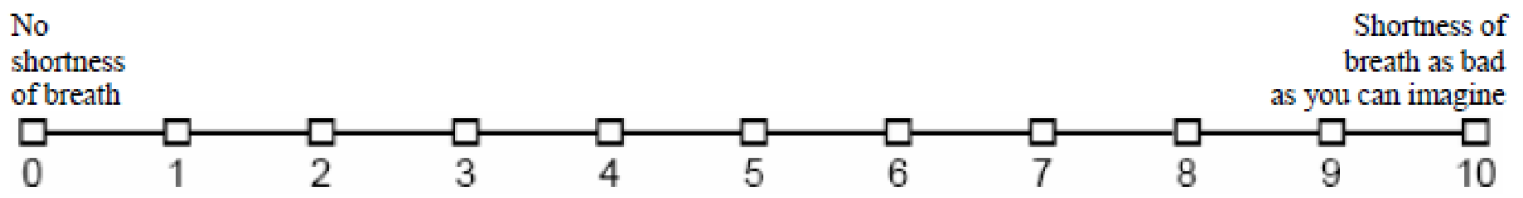

3. What was your activity level just before your shortness of breath was at its worst between this morning and until now?

Resting (For example: sitting or lying down)

Mild (For example: walking within your home, bathing, or dressing)

Moderate (For example: walking while carrying a light load, sweeping floors, or vacuuming)

Vigorous (For example: walking briskly, dancing, or climbing stairs)

4. Please rate the difficulty you had clearing the phlegm/mucus from your lungs when it was at its worst between this morning and until now.

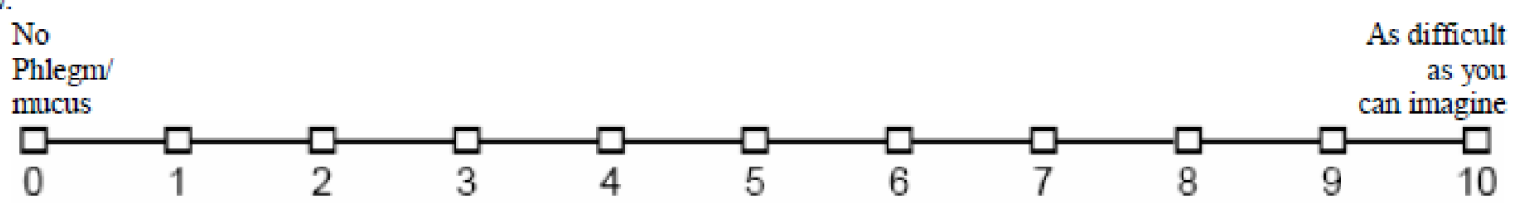

5. Please rate the severity of your chest tightness when it was at its worst between this morning and until now.

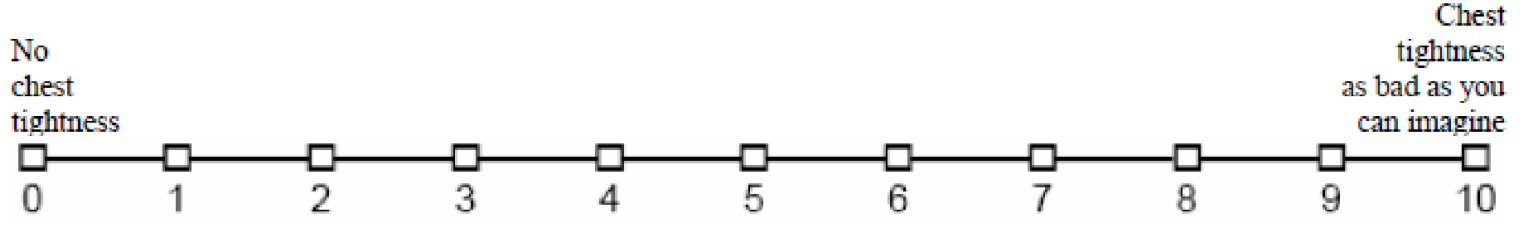

6. Please rate the severity of your wheezing when it was at its worst between this morning and until now.

Wheezing

Figure SI (Continued). 


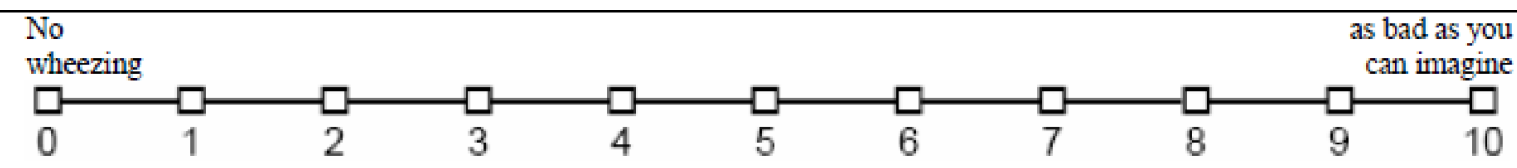

7. Please rate the severity of your coughing when it was at its worst between this morning and until now.

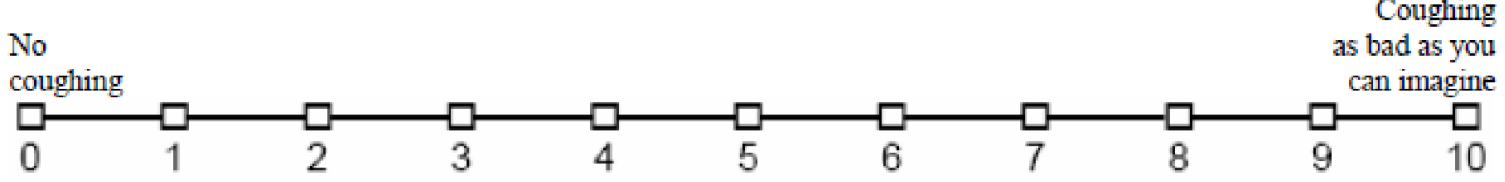

8. Please rate how bothered you were by your COPD symptoms between this morning and until now.

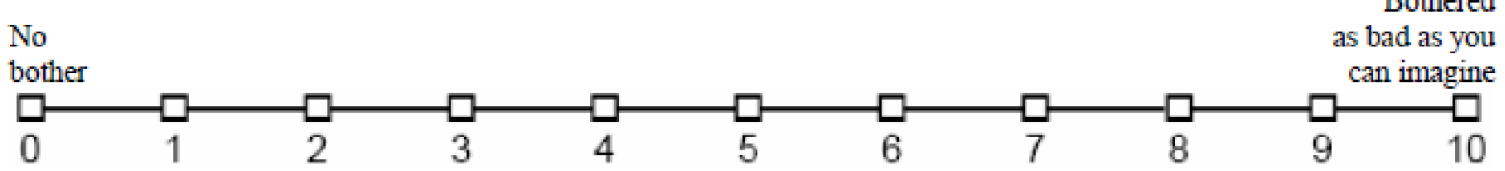

9. Please rate how difficult your COPD symptoms made it for you to move around or do your activities between this morning and until now.

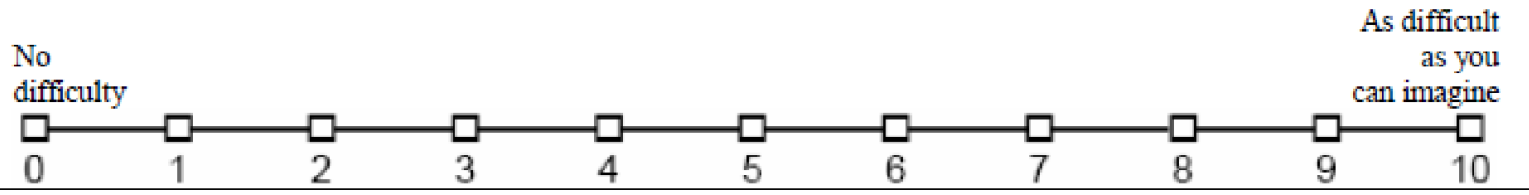

\section{Complete WEEKLY in the evening}

1. Since the start of the study, how would you rate the overall impact of COPD on your life right now?

$\begin{array}{ll}\square & \text { a great deal worse } \\ \square & \text { moderately worse } \\ \square & \text { a little worse } \\ \square & \text { about the same } \\ \square & \text { a little better } \\ \square & \text { moderately better } \\ \square & \text { great deal better }\end{array}$

2. Since the start of the study, how would you rate the severity of your current COPD symptoms?

$\begin{array}{ll}\square & \text { a great deal worse } \\ \square & \text { moderately worse } \\ \square & \text { a little worse } \\ \square & \text { about the same } \\ \square & \text { a little better } \\ \square & \text { moderately better } \\ \square & \text { great deal better }\end{array}$

Figure SI COPD exploratory eDiary (English for UK version). 
They were considered "worse" if $\mathrm{FEV}_{1}$ decreased by at least $120 \mathrm{~mL}$ between baseline and week 26 and ratings on the global change items of the diary on the week 26 rating indicate worsening (ie, "a little worse", "moderately worse", or "a great deal worse" for both items). The remaining patients were classified as "uncertain/no change". Anchor-based methods used an external criterion to categorize patients into groups reflecting an a priori determined change grouping (eg, "no change", "large improvement", and "large deterioration"). The method used was similar to that for sensitivity, but used only the global change item.

To evaluate the consistency of treatment response across the severity range, cumulative distribution curves, using unblinded data for the five treatment groups, were produced using the change scores of the COPD eDiary total scores (both actual point change and percentage change).

\section{Results}

\section{Correlations between symptom severity} and bother/difficulty with activities scores

For other symptoms, correlations with impact items were lower but still substantial (0.64-0.86). Regression modeling showed that "shortness of breath" was a highly significant $(p<0.0001)$ predictor of bother ratings, with no other symptom showing a significant association once shortness of breath had been taken into account.

\section{Validity of eDiary}

For SGRQ, the correlation pattern for the activity and impact subscales was similar to that of baseline dyspnea index, with difficulty with activities, "bother", and shortness of breath showing the highest correlations. Two of the three highest values within columns were as predicted, whereas the third, that is, the correlation between eDiary difficulty with activities and SGRQ symptoms was not as predicted. Thus, the observed pattern only partly fulfilled the predictions (Table S1).

\section{Consistency of treatment response over the severity range}

If an improvement of 0.6 points on the mean total score was considered as the criterion for defining responders, it was found that the QVA149 treatment was associated with approximately a $50 \%$ response rate compared with a $30 \%$ response rate in placebo (Figure S2).

Table SI Correlations of eDiary items and summary scores against BDI and SGRQ score

\begin{tabular}{|c|c|c|c|c|c|c|c|}
\hline \multirow{3}{*}{$\begin{array}{l}\text { Diary } \\
\text { item }\end{array}$} & \multirow[t]{3}{*}{ With variable } & \multicolumn{3}{|c|}{ Correlation coefficient } & \multirow{3}{*}{$\begin{array}{l}\text { Coefficient of } \\
\text { determination } \\
\left(r^{2}\right)\end{array}$} & \multirow[t]{3}{*}{$p$-value } & \multirow{3}{*}{$\begin{array}{l}95 \% \\
\text { confidence } \\
\text { interval }\end{array}$} \\
\hline & & \multirow{2}{*}{$\begin{array}{l}\mathbf{N} \\
\text { overall }\end{array}$} & Spearman & Pearson & & & \\
\hline & & & \multicolumn{2}{|c|}{$\overline{\text { (over three daily assessments) }}$} & & & \\
\hline \multirow[t]{7}{*}{ SB } & BDI: magnitude of effort & 173 & -0.504 & -0.509 & 0.2593 & $<0.0001$ & $-0.612,-0.390$ \\
\hline & BDI: functional impairment & $17 \mid$ & -0.319 & -0.324 & 0.1050 & $<0.0001$ & $-0.452,-0.183$ \\
\hline & $\begin{array}{l}\text { BDI: magnitude of task } \\
\text { (at normal pace) }\end{array}$ & 173 & -0.412 & -0.452 & 0.2039 & $<0.0001$ & $-0.563,-0.324$ \\
\hline & SGRQ: activity score & 173 & 0.584 & 0.567 & 0.3220 & $<0.0001$ & $0.457,0.661$ \\
\hline & SGRQ: impacts score & 173 & 0.618 & 0.613 & 0.3753 & $<0.0001$ & $0.510,0.698$ \\
\hline & SGRQ: symptoms score & 173 & 0.576 & 0.553 & 0.3056 & $<0.0001$ & $0.440,0.649$ \\
\hline & SGRQ: total score & 173 & 0.651 & 0.655 & 0.4290 & $<0.0001$ & $0.56 \mathrm{I}, 0.733$ \\
\hline \multirow[t]{7}{*}{ PM } & BDI: magnitude of effort & 173 & -0.233 & -0.304 & 0.0923 & $<0.0001$ & $-0.433,-0.162$ \\
\hline & BDI: functional impairment & 171 & -0.177 & -0.208 & 0.0435 & 0.0061 & $-0.348,-0.060$ \\
\hline & $\begin{array}{l}\text { BDI: magnitude of task } \\
\text { (at normal pace) }\end{array}$ & 173 & -0.174 & -0.266 & 0.0706 & 0.0004 & $-0.399,-0.121$ \\
\hline & SGRQ: activity score & 173 & 0.244 & 0.288 & 0.0828 & 0.0001 & $0.145,0.419$ \\
\hline & SGRQ: impacts score & 173 & 0.392 & 0.396 & 0.1568 & $<0.0001$ & $0.262,0.515$ \\
\hline & SGRQ: symptoms score & 173 & 0.443 & 0.448 & 0.2003 & $<0.0001$ & $0.320,0.559$ \\
\hline & SGRQ: total score & 173 & 0.371 & 0.412 & 0.1695 & $<0.0001$ & $0.280,0.528$ \\
\hline \multirow[t]{3}{*}{ CT } & BDI: magnitude of effort & 173 & -0.475 & -0.464 & 0.2153 & $<0.0001$ & $-0.573,-0.338$ \\
\hline & BDI: functional impairment & $17 \mid$ & -0.274 & -0.267 & 0.0711 & 0.0004 & $-0.401,-0.122$ \\
\hline & $\begin{array}{l}\text { BDI: magnitude of task } \\
\text { (at normal pace) }\end{array}$ & 173 & -0.371 & -0.417 & 0.1737 & $<0.0001$ & $-0.533,-0.285$ \\
\hline
\end{tabular}


Table SI (Continued)

\begin{tabular}{|c|c|c|c|c|c|c|c|}
\hline \multirow{3}{*}{$\begin{array}{l}\text { Diary } \\
\text { item }\end{array}$} & \multirow[t]{3}{*}{ With variable } & \multicolumn{3}{|c|}{ Correlation coefficient } & \multirow{3}{*}{$\begin{array}{l}\text { Coefficient of } \\
\text { determination } \\
\left(r^{2}\right)\end{array}$} & \multirow[t]{3}{*}{$p$-value } & \multirow{3}{*}{$\begin{array}{l}95 \% \\
\text { confidence } \\
\text { interval }\end{array}$} \\
\hline & & \multirow{2}{*}{$\begin{array}{l}\mathbf{N} \\
\text { overall }\end{array}$} & Spearman & Pearson & & & \\
\hline & & & \multicolumn{2}{|c|}{$\overline{\text { (over three daily assessments) }}$} & & & \\
\hline & SGRQ: activity score & 173 & 0.521 & 0.499 & 0.2492 & $<0.000 \mathrm{I}$ & $0.378,0.603$ \\
\hline & SGRQ: impacts score & 173 & 0.558 & 0.548 & 0.2998 & $<0.0001$ & $0.434,0.644$ \\
\hline & SGRQ: symptoms score & 173 & 0.559 & 0.546 & 0.2977 & $<0.0001$ & $0.432,0.642$ \\
\hline & SGRQ: total score & 173 & 0.595 & 0.592 & 0.3505 & $<0.0001$ & $0.486,0.68 I$ \\
\hline \multirow[t]{7}{*}{ WH } & BDI: magnitude of effort & 173 & -0.339 & -0.394 & 0.1549 & $<0.000$ I & $-0.513,-0.260$ \\
\hline & BDI: functional impairment & $17 \mid$ & -0.242 & -0.259 & 0.0670 & 0.0006 & $-0.394,-0.113$ \\
\hline & $\begin{array}{l}\text { BDI: magnitude of task } \\
\text { (at normal pace) }\end{array}$ & 173 & -0.313 & -0.387 & 0.1495 & $<0.0001$ & $-0.507,-0.252$ \\
\hline & SGRQ: activity score & 173 & 0.407 & 0.431 & 0.1857 & $<0.0001$ & $0.30 \mathrm{I}, 0.545$ \\
\hline & SGRQ: impacts score & 173 & 0.482 & 0.488 & 0.2385 & $<0.0001$ & $0.366,0.594$ \\
\hline & SGRQ: symptoms score & 173 & 0.597 & 0.566 & 0.3209 & $<0.0001$ & $0.456,0.660$ \\
\hline & SGRQ: total score & 173 & 0.515 & 0.537 & 0.2887 & $<0.0001$ & $0.422,0.636$ \\
\hline \multirow[t]{7}{*}{$\mathrm{CO}$} & BDI: magnitude of effort & 173 & -0.232 & -0.306 & 0.0934 & $<0.000$ I & $-0.435,-0.164$ \\
\hline & BDI: functional impairment & 171 & -0.150 & -0.207 & 0.0427 & 0.0066 & $-0.346,-0.058$ \\
\hline & $\begin{array}{l}\text { BDI: magnitude of task } \\
\text { (at normal pace) }\end{array}$ & 173 & -0.215 & -0.264 & 0.0698 & 0.0004 & $-0.398,-0.120$ \\
\hline & SGRQ: activity score & 173 & 0.231 & 0.297 & 0.0885 & $<0.0001$ & $0.155,0.428$ \\
\hline & SGRQ: impacts score & 173 & $0.34 I$ & 0.406 & 0.1645 & $<0.0001$ & $0.273,0.523$ \\
\hline & SGRQ: symptoms score & 173 & 0.468 & 0.475 & 0.2252 & $<0.0001$ & $0.350,0.583$ \\
\hline & SGRQ: total score & 173 & 0.349 & 0.426 & 0.1811 & $<0.0001$ & $0.295,0.540$ \\
\hline \multirow[t]{7}{*}{ BO } & BDI: magnitude of effort & 173 & -0.516 & -0.507 & 0.2572 & $<0.0001$ & $-0.610,-0.387$ \\
\hline & BDI: functional impairment & $17 \mid$ & -0.332 & -0.343 & 0.1179 & $<0.0001$ & $-0.469,-0.204$ \\
\hline & $\begin{array}{l}\text { BDI: magnitude of task } \\
\text { (at normal pace) }\end{array}$ & 173 & -0.395 & -0.435 & 0.1889 & $<0.0001$ & $-0.548,-0.305$ \\
\hline & SGRQ: activity score & 173 & 0.564 & 0.547 & 0.2987 & $<0.0001$ & $0.433,0.643$ \\
\hline & SGRQ: impacts score & 173 & 0.634 & 0.621 & 0.3860 & $<0.0001$ & $0.520,0.705$ \\
\hline & SGRQ: symptoms score & 173 & $0.54 I$ & 0.534 & 0.2855 & $<0.0001$ & $0.418,0.633$ \\
\hline & SGRQ: total score & 173 & 0.646 & 0.649 & 0.4208 & $<0.0001$ & $0.553,0.728$ \\
\hline \multirow[t]{7}{*}{ DI } & BDI: magnitude of effort & 173 & -0.525 & -0.518 & 0.2683 & $<0.0001$ & $-0.619,-0.400$ \\
\hline & BDI: functional impairment & $17 \mid$ & -0.358 & -0.364 & 0.1325 & $<0.0001$ & $-0.488,-0.226$ \\
\hline & $\begin{array}{l}\text { BDI: magnitude of task } \\
\text { (at normal pace) }\end{array}$ & 173 & -0.421 & -0.456 & 0.2081 & $<0.0001$ & $-0.567,-0.329$ \\
\hline & SGRQ: activity score & 173 & 0.610 & 0.578 & 0.3337 & $<0.0001$ & $0.469,0.669$ \\
\hline & SGRQ: impacts score & 173 & 0.647 & 0.627 & 0.3935 & $<0.0001$ & $0.527,0.710$ \\
\hline & SGRQ: symptoms score & 173 & 0.560 & 0.538 & 0.2896 & $<0.0001$ & $0.423,0.636$ \\
\hline & SGRQ: total score & 173 & 0.676 & 0.664 & 0.4410 & $<0.0001$ & $0.57 I, 0.740$ \\
\hline Symptoms & BDI: magnitude of effort & 173 & -0.433 & $-0.44 I$ & 0.1947 & $<0.0001$ & $-0.554,-0.313$ \\
\hline \multirow[t]{6}{*}{ mean } & BDI: functional impairment & $17 \mid$ & -0.282 & -0.281 & 0.0790 & 0.0002 & $-0.414,-0.137$ \\
\hline & $\begin{array}{l}\text { BDI: magnitude of task } \\
\text { (at normal pace) }\end{array}$ & 173 & -0.349 & -0.399 & 0.1592 & $<0.0001$ & $-0.517,-0.266$ \\
\hline & SGRQ: activity score & 173 & 0.485 & 0.466 & 0.2170 & $<0.0001$ & $0.340,0.575$ \\
\hline & SGRQ: impacts score & 173 & 0.577 & 0.547 & 0.2990 & $<0.000$ I & $0.433,0.644$ \\
\hline & SGRQ: symptoms score & 173 & 0.609 & 0.577 & 0.3334 & $<0.0001$ & $0.469,0.669$ \\
\hline & SGRQ: total score & 173 & 0.596 & 0.585 & 0.3427 & $<0.0001$ & $0.478,0.676$ \\
\hline \multirow[t]{3}{*}{ Total mean } & BDI: magnitude of effort & 173 & -0.469 & -0.471 & 0.2215 & $<0.0001$ & $-0.579,-0.346$ \\
\hline & BDI: functional impairment & $17 \mid$ & -0.300 & -0.307 & 0.0943 & $<0.0001$ & $-0.437,-0.165$ \\
\hline & $\begin{array}{l}\text { BDI: magnitude of task } \\
\text { (at normal pace) }\end{array}$ & 173 & -0.372 & -0.421 & 0.1774 & $<0.0001$ & $-0.537,-0.290$ \\
\hline
\end{tabular}


Table SI (Continued)

\begin{tabular}{|c|c|c|c|c|c|c|c|}
\hline \multirow{3}{*}{$\begin{array}{l}\text { Diary } \\
\text { item }\end{array}$} & \multirow[t]{3}{*}{ With variable } & \multicolumn{3}{|c|}{ Correlation coefficient } & \multirow{3}{*}{$\begin{array}{l}\text { Coefficient of } \\
\text { determination } \\
\left(r^{2}\right)\end{array}$} & \multirow[t]{3}{*}{$p$-value } & \multirow{3}{*}{$\begin{array}{l}95 \% \\
\text { confidence } \\
\text { interval }\end{array}$} \\
\hline & & \multirow{2}{*}{$\begin{array}{l}\mathbf{N} \\
\text { overall }\end{array}$} & Spearman & Pearson & & & \\
\hline & & & \multicolumn{2}{|c|}{$\overline{\text { (over three daily assessments) }}$} & & & \\
\hline & SGRQ: activity score & 173 & 0.525 & 0.502 & 0.2523 & $<0.0001$ & $0.382,0.606$ \\
\hline & SGRQ: impacts score & 173 & 0.608 & $0.58 \mathrm{I}$ & 0.3374 & $<0.0001$ & $0.473,0.672$ \\
\hline & SGRQ: symptoms score & 173 & 0.603 & 0.579 & 0.3350 & $<0.0001$ & $0.470,0.670$ \\
\hline & SGRQ: total score & 173 & 0.628 & 0.618 & 0.3821 & $<0.0001$ & $0.517,0.703$ \\
\hline
\end{tabular}

Notes: $P$-values and $95 \%$ confidence limits, based on Fisher's z transformation (without bias adjustment), are provided for the Pearson correlation coefficients. $P$-values test for statistically significant correlation between the two variables; Symptoms include SB, PM, CT, WH, and CO.

Abbreviations: BDI, baseline dyspnea index; BO, bothered; CO, coughing; CT, chest tightness; DI, difficulty; eDiary, electronic patient diary; PM, phlegm/mucus; SB, shortness of breath; SGRQ, St George's Respiratory Questionnaire; WH, wheezing.

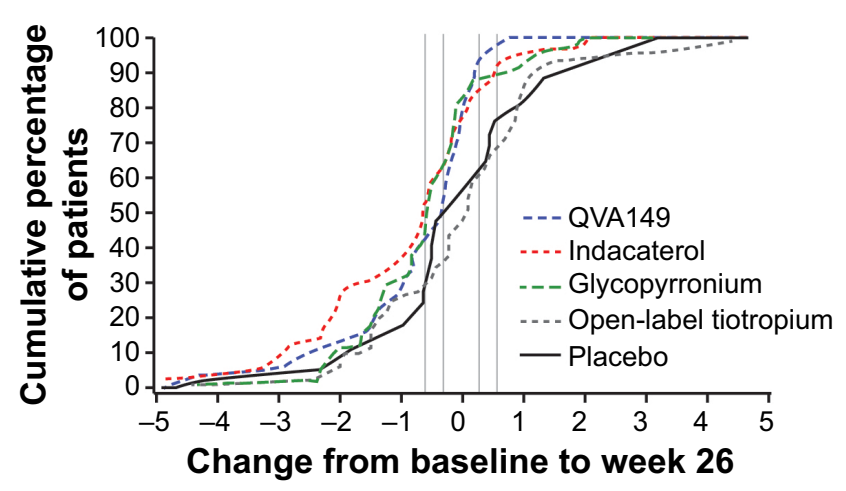

Figure S2 Cumulative distribution curves (point change) for the eDiary mean total score over all three time frames.

Abbreviation: eDiary, electronic patient diary.

\section{References}

1. Bateman ED, Ferguson GT, Barnes N, et al. Dual bronchodilation with QVA149 versus single bronchodilator therapy: the SHINE study. Eur Respir J. 2013;42(6):1484-1494.

2. Baldwin MJ, Kulich K, Tiplady B, Gwaltney C, Cline J. Evaluation of an electronic daily diary for measuring morning symptoms in chronic obstructive pulmonary disease. Am J Respir Crit Care Med. 2013;187: A2517.

3. Baldwin M, Kulich K, Tiplady B, Gwaltney C, Cline J. Symptoms and impact of COPD assessed by a handheld electronic diary. Poster presented at: 2013 Meeting of the European Respiratory Society; September 7-11, 2013; Barcelona, Spain. Poster P4903.
International Journal of COPD

\section{Publish your work in this journal}

The International Journal of COPD is an international, peer-reviewed journal of therapeutics and pharmacology focusing on concise rapid reporting of clinical studies and reviews in COPD. Special focus is given to the pathophysiological processes underlying the disease, intervention programs, patient focused education, and self management protocols.

\section{Dovepress}

This journal is indexed on PubMed Central, MedLine and CAS. The manuscript management system is completely online and includes a very quick and fair peer-review system, which is all easy to use. Visit $\mathrm{http} / / / \mathrm{www}$.dovepress.com/testimonials.php to read real quotes from published authors. 